University of Nebraska - Lincoln

DigitalCommons@University of Nebraska - Lincoln

1996

\title{
Conifer Shoot Bidirectional Scattering: Methodology and Preliminary Results
}

\author{
E.A. Walter-Shea \\ University of Nebraska - Lincoln \\ M.A. Mesarch \\ University of Nebraska - Lincoln
}

Follow this and additional works at: https://digitalcommons.unl.edu/natrespapers

Part of the Natural Resources and Conservation Commons, Natural Resources Management and Policy Commons, and the Other Environmental Sciences Commons

Walter-Shea, E.A. and Mesarch, M.A., "Conifer Shoot Bidirectional Scattering: Methodology and Preliminary Results" (1996). Papers in Natural Resources. 1410.

https://digitalcommons.unl.edu/natrespapers/1410

This Article is brought to you for free and open access by the Natural Resources, School of at DigitalCommons@University of Nebraska - Lincoln. It has been accepted for inclusion in Papers in Natural Resources by an authorized administrator of DigitalCommons@University of Nebraska - Lincoln. 


\title{
Conifer Shoot Bidirectional Scattering: Methodology and Preliminary Results
}

\author{
Elizabeth A. Walter-Shea, Mark A. Mesarch and Liqiang Chen \\ Department of Agricultural Meteorology, University of Nebraska \\ 246 L.W. Chase Hall, Lincoln, NE 68583-0728 \\ voice: 402-472-1553/ FAX: 402-472-6614/agme012@unlvm.unl.edu
}

\begin{abstract}
Biophysical models describing radiant energy partitioning at the surface are dependent on our knowledge of the distribution of radiation on canopy elements and resulting interactions (i.e., reflectance, transmittance and absorptance) as well as on the existing state of coupled physiological parameters (such as stomatal conductance and photosynthesis). However, research on optical properties of coniferous forest canopy elements, particularly at the conifer shoot level, has been limited. The objective of this paper is to describe the methodology developed in the investigation of scattering from boreal forest conifer shoots and to present preliminary results using the methodology. An automated goniometer system and procedure were developed for characterizing the bidirectional scattering of conifer shoots. The system includes a computercontrolled goniometer, an SE-590 spectroradiometer, projected area device, sample stand, reference panel and artificial light source. Preliminary results of conifer shoot scattering indicate backscattering and forward scattering features specific to illumination-view-shoot geometries. The methodology presented offers an automated and fairly simple means of characterizing the bidirectional scattering from canopy elements where numerous measures are required. Such measurements are important in advancing our understanding regarding the dynamics of shoot-level absorptance of solar energy for physiological processes and interpreting remotelysensed canopy reflectance in radiative transfer parameterization.
\end{abstract}

\section{INTRODUCTION}

Biophysical models describing radiant energy partitioning at the surface are dependent on our knowledge of the distribution of radiation on canopy elements and resulting interactions as well as on the existing state of coupled physiological parameters. Photosynthetically active radiation (PAR) is the source of energy for the fixation of carbon dioxide via photosynthesis; thus it is essential to understand the absorptance of PAR by canopy elements within a stand to understand canopy fluxes of $\mathrm{CO}_{2}$ and water vapor. In addition, physiological processes are affected by absorptance of nearinfrared (NIR) and longer wavelengths, i.e., the canopy element radiation balance. The heterogeneous structure of coniferous stands contributes to the difficulty in modeling coniferous canopy processes in a realistic yet simple manner [1,2]. Refinement of existing three-dimensional radiation transfer models is needed to account for the complex architecture and the interaction of radiation with canopy elements displayed within these vegetation-filled objects, e.g., needle, twig, shoot and branch radiation scattering and absorption. However, research on optical properties of coniferous forest canopy elements, particularly at the conifer shoot level, has been limited (e.g., $[3,4])$. This may be due to the difficulties in collecting data, the expense in making measurements within and above forest canopies, and past research emphasis on agricultural crops [3].

Leaves, needles and bark are canopy elements which are important in scattering radiation in boreal forest vegetation [5]. Needle and bark properties can vary considerably depending on age and height in the canopy; elements deep in the canopy may be covered with algae and fungi and shade-induced effects on shoot development may exist $[5,6]$. In the NIR portion of the electromagnetic spectrum little radiation is absorbed so that scattering by canopy elements will be significant. In contrast, needles absorb a large portion of PAR [3, 7]. Conifer needles absorb more PAR than deciduous leaves; twigs, especially current year's growth, also absorb PAR [3]. Differences in the magnitude of reflectance between conifer shoots and individual needles, particularly in the NIR and especially in older shoots, have been reported [4]. The difference was attributed to the contribution of the more mature branch bark in the older branches.

Materials presented are only a part of a larger investigation in the Boreal Ecosystem-Atmospheres Study (BOREAS) [8] on the coupling between radiation and gas exchange of canopy elements in a boreal forest; characterization of radiation interaction with conifer shoots through measurement and modelling is required. To achieve this an automated goniometer system was developed for characterizing the bidirectional scattering of conifer shoots. The system includes a computercontrolled goniometer, an SE-590 spectrometer (Spectron Engineering, Denver, $\mathrm{CO}$ ), sample stand, reference panel, light source and projected area device. The objective of this paper is to describe the methodology developed and to present preliminary results using the methodology.

\section{METHODS}

Radiative scattering from conifer shoots was characterized using the bidirectional reflectance factor (BRF). Conifer shoots were oriented in an azimuth relative to the light source azimuth, 
designated as $\phi_{\text {shool. }}$. Illumination, view and shoot orientation are represented as direction $\left(\theta_{\mathrm{i}}, \phi_{i} ; \theta_{r}, \phi_{r} ; \phi_{\text {shool }}\right)$ where $\theta$ is the zenith angle, $\phi$ is the azimuth angle, ' $i$ ' indicates illumination direction and ' $r$ ' indicates the reflected direction. Thus, the BRF for a particular illumination-view-shoot geometry is defined as:

$$
\operatorname{BRF}\left(\theta_{i}, \phi_{i} ; \theta_{r}, \phi_{r} ; \phi_{\text {shoot }}\right)=\frac{\Phi_{r}\left(\theta_{i}, \phi_{i} ; \theta_{r}, \phi_{r} ; \phi_{\text {shoot }}\right)}{\Phi_{r, \text { id }}\left(\theta_{i}, \phi_{i} ; \theta_{r}, \phi_{r} ; \phi_{\text {shoot }}\right)}
$$

i.e., the ratio of the reflected (scattered) flux $\left[\Phi_{r}\left(\theta_{i}, \phi_{i} ; \theta_{r}, \phi_{r} ; \phi_{\text {shoot }}\right)\right]$ from the shoot to the reflected flux from an ideal Lambertian surface $\left[\Phi_{\mathrm{r}, \mathrm{id}}\left(\boldsymbol{\theta}_{\mathrm{i}}, \boldsymbol{\phi}_{\mathrm{i}} ; \boldsymbol{\theta}_{\mathrm{r}}, \boldsymbol{\phi}_{\mathrm{r}} ; \boldsymbol{\phi}_{\text {shoot }}\right)\right]$ [9]. Output from the SE-590 is proportional to the scattered radiant flux. The scattered flux from an ideal Lambertian surface $\left[\Phi_{r, i d}\left(\theta_{i}, 0 ; \theta_{r}, \phi_{r} ; \phi_{\text {shoot }}\right)\right]$ was estimated from a nadir-viewed calibrated Spectralon reference panel (Labsphere, Inc., North Sutton, NH) illuminated under the same conditions as the sample $\left[\Phi_{r, \text { ref }}\left(\boldsymbol{\theta}_{i}, 0 ; 0, \phi_{r} ; \phi_{\text {shoot }}\right)\right]$. Nadir-viewed fluxes from the reference panel were corrected for the horizontal projected area of the sample [i.e., projected area in the direction of the light source $\left(A_{\theta i, \phi s h o o t}\right)$ divided by $\left.\cos \theta_{i}\right]$ and for view angle $\left(\cos \theta_{r}\right)$ to represent the reflected flux from an ideal Lambertian surface:

$$
\begin{aligned}
\Phi_{r, \mathrm{~d} d}\left(\boldsymbol{\theta}_{\mathrm{i}}, 0 ; \boldsymbol{\theta}_{\mathrm{r}}, \phi_{\mathrm{r}} ; \phi_{\text {shoot }}\right)=\frac{\mathrm{A}_{\theta \mathrm{i}, \phi s h o o t}}{\mathrm{~A}_{\mathrm{ref}} \cdot \cos \theta_{\mathrm{i}}} \\
\cdot \Phi_{\mathrm{r}, \text { ref }}\left(\boldsymbol{\theta}_{\mathrm{i}}, 0 ; 0, \phi_{\mathrm{r}} ; \boldsymbol{\phi}_{\text {shoot }}\right) \cdot \cos \theta_{\mathrm{r}} \cdot \operatorname{CF}\left(\theta_{\mathrm{i}}\right) .
\end{aligned}
$$

$\mathrm{A}_{\text {ref }}$ is the area of the spot size as "seen" from the SE590 in the nadir position, $\cos \theta_{\mathrm{r}}$ corrects the flux for that in the scattered direction, and $\operatorname{CF}\left(\theta_{i}\right)$ is the calibration factor for the reference panel. The target was illuminated by a light source with an output within the $400-900 \mathrm{~nm}$ range from a quartzline projection lamp characterized with a $2^{\circ}$ divergent beam and irradiance variation of $5 \%$ along the minor axis and $12 \%$ along the major axis of the illuminated spot.

The projected area of the sample was estimated using an imaging camera with the shoot sample suspended by nylon monofilament line within a sample ring positioned over a light table. The sample ring was rotated and tilted so that the sample was projected in the same direction toward the imaging camera as it was toward the light source for scattered flux measurements (yielding projected area, $A_{\theta i, \phi s h o o t}$ ). Once the projected area for each illumination and shoot orientation condition was measured for a particular shoot, the sample ring was removed from the imaging system with the shoot sample still in place and then mounted under the goniometer for scattered flux measurements. The cut end of the sample was kept in a water-filled vial at all times to reduce moisture loss from the sample.
Bidirectional scattering of shoots was measured using an SE-590 spectrometer with a $6^{\circ}$ field of view mounted on the automated goniometer yielding a $3.75 \mathrm{~cm}$ diameter target spot. A constant distance of $36.5 \mathrm{~cm}$ was maintained between the sample and sensor at all view angles. Shoot segment length was limited to $2.5 \mathrm{~cm}$ to maintain the shoot sample within the SE590 spot size at all view angles and to maximize the sample area within the spot size. Samples were mounted horizontally in a sample ring at various azimuthal orientations $\left(\phi_{\text {shoot }}\right)$ relative to the illumination azimuth so as to capture variations due to sample-light geometry. Scattered radiant flux from the shoot was measured at selected view zenith and azimuth angles and illumination angles.

\section{RESULTS}

Scattering from conifer shoots can be complex as indicated from bidirectional reflectance factors from jack pine (Pinus banksiana) shoots. Preliminary results indicate view direction had a much greater effect on scattering than did illumination angle (Fig. 1). Shoot orientation relative to the light source altered the sunlit and shaded portions of conifer shoot in the direction of the sensor so that $\phi_{\text {shoot }}$ had a similar effect on scattering from conifer shoots as did view angle (Fig. 2). Backscattering and forward scattering features varied for particular shoot-view geometries (data not shown).

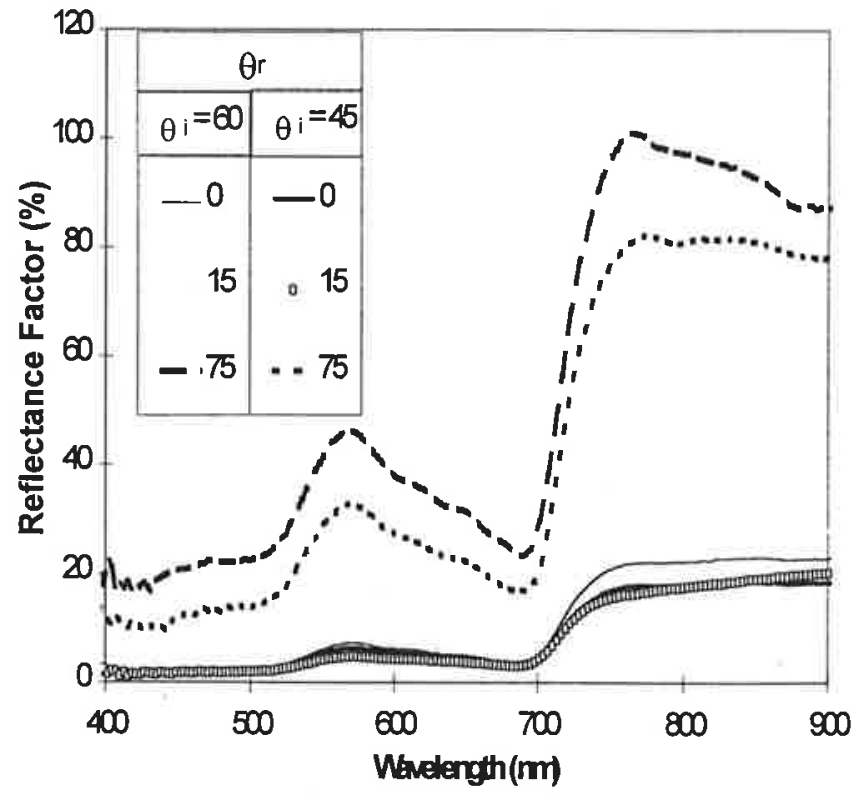

Fig. 1. Spectral bidirectional reflectance factors for a jack pine (Pinus banksiana) shoot oriented with the shoot tip directed away from the illumination azimuth $\left(\phi_{\text {shoot }}=0^{\circ}\right)$ and illuminated at zenith angles $\left(\theta_{\mathrm{i}} \mathrm{s}\right)$ of $45^{\circ}$ and $60^{\circ}$ viewed at azimuth angles $\left(\phi_{\mathrm{r}}\right)$ of $20^{\circ}$. 


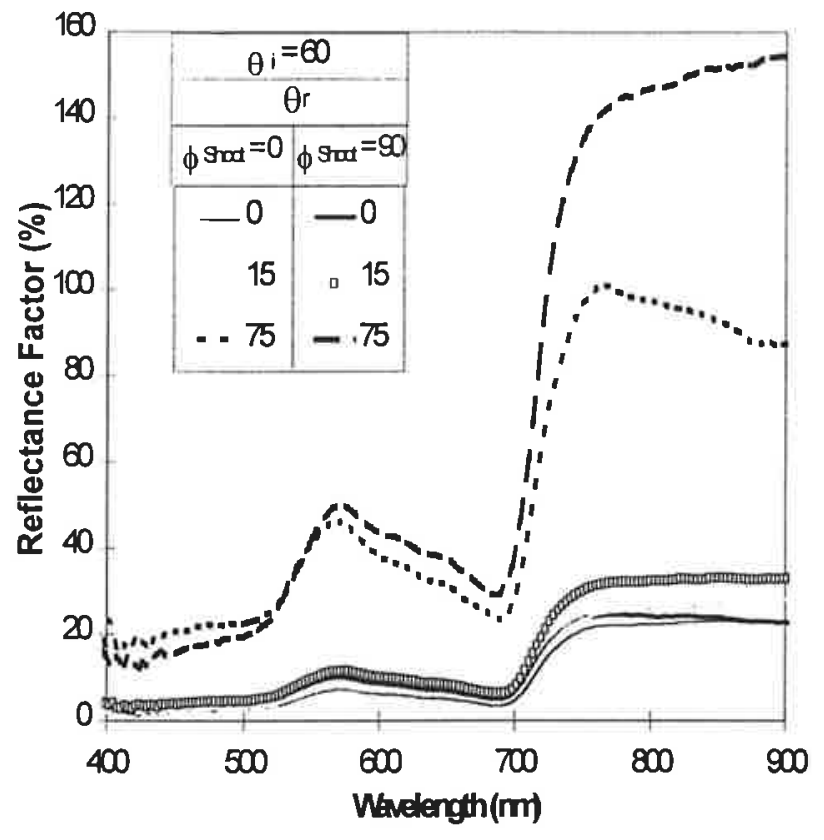

Fig. 2. Spectral bidirectional reflectance factors for a jack pine (Pinus banksiana) shoot illuminated at zenith angle $\left(\theta_{i}\right)$ of $60^{\circ}$ and oriented with the shoot tip directed away from the illumination azimuth $\left(\phi_{\text {shoot }}=0^{\circ}\right)$ and oriented with the shoot axis perpendicular to the illumination azimuth $\left(\phi_{\text {shoot }}=90^{\circ}\right)$. Shoot was viewed at an azimuth $\left(\phi_{\mathrm{r}}\right)$ of $20^{\circ}$.

\section{DISCUSSION}

The methodology presented offers an automated and fairly simple means of characterizing the bidirectional scattering from canopy elements where numerous measures are required. Such measurements are important in advancing our understanding regarding the dynamics of shoot-level absorptance of solar energy for physiological processes and interpreting remotelysensed canopy reflectance in radiative transfer parameterization. Our overall goal is to analyze and synthesize field data through the use of mathematical models of conifer shoot radiative properties and gas exchange. The measurements of shoot scattering will enable us to test models of shoot radiative scattering and absorption in a step toward accomplishing our overall goal.

\section{ACKNOWLEDGMENTS}

We acknowledge the support by NOAA's Office of Climate and Global Change Program of our BOREAS research through grant NA36GP0281. We also thank J. Wurm (Li-Cor, Inc., Lincoln, NE) for assistance in the design of the light source.

\section{REFERENCES}

[1] D.L. Peterson and S.W. Running, "Applications in forest science and management," in Theory and Applications of Optical Remote Sensing, G. Asrar, Ed. New York: John Wiley \& Sons, 1989, pp. 429-473.

[2] P. Oker-Blom, J. Lappi, and H. Smolander, "Radiation regime and photosynthesis of coniferous stands," in PhotonVegetation Interactions, R.B. Myneni and J. Ross, Eds. New York: Springer-Verlag, 1991, pp. 469-499.

[3] D.L. Williams, "A comparison of spectral reflectance properties at the needle, branch, and canopy level for selected conifer species," Remote Sens. Environ., vol. 35, pp. 79-93, 1991.

[4] B.N. Rock, D.L. Williams, D.M. Moss, G.N. Lauten, and M. Kim, "High-spectral resolution field and laboratory optical reflectance measurements of red spruce and eastern hemlock needles and branches," Remote Sens. Environ., vol. 47, pp. 176-189, 1994.

[5] J.M. Norman and P.G. Jarvis, "Photosynthesis in Sitka spruce [Picea sitchensis (Bong,) Carr.] V. Radiation penetration theory and a test case," J. Appl. Ecol., vol. 12(3), pp. 839-878, 1974.

[6] W.K. Smith and G.A. Carter, "Shoot structural effects on needle temperatures and photosynthesis in conifers," Amer. $J$. of Bot., vol. 75, pp. 496-500, 1988.

[7] C.S.T. Daughtry, L.L. Biehl, and K.J. Ranson, "A new technique to measure the spectral properties of conifer needles," Remote Sens. Environ., vol. 27, pp. 81-91, 1989.

[8] P. Sellers et al., "The Boreal Ecosystem-Atmosphere Study (BOREAS): An overview and early results from the 1994 field year," Bull. Amer. Meteorol. Soc., vol. 76, pp. 1549$1577,1995$.

[9] F.E. Nicodemus, J.C. Richmond, J.J. Hsia, I.W. Ginsberg, and T. Limperis, Geometrical considerations and Nomenclature for Reflectance, NBS Monograph 160, U.S. Government Printing Office, Washington, D.C., 1977. 


\section{IEEE COPYRIGHT FORM}

The IEEE has developed this form with great care and with the best interests of its members and contributing authors in mind. Therefore, in order to maintain uniform treatment among all contributors. Company or other forms may not be substituted for this form, nor may any wording of this form be changed. This form is intended for original, previously unpublished material submitted to IEEE periodicals and conference publications. This form, when completed, must accompany any such material in order to be published by IEEE. Please read it carefully and keep a copy of it for your files.

TITLE OF WORK (hereinafter, "the work"): Conifer Shoof Bidirectional Scatfering:
Methodology and Preliminary Results AUTHOR(S): Elizabeth A. Walter-Shea, Mark A. Mesarch, and Liqiang Chen PUBLICATION TITLE/DATE: 1996 IEEE International Geoscience and Remote Sensing Symposium, May 27-31

$$
\text { PART A -- COPYRIGHT TRANSFER FORM }
$$

(US. Government employes whose work is not subject to US. copyright should so certify by signing Part B overleal. Authors of works subject to Crown Copyright should sign Part C overleaf

The undersigned hereby assigns all copyright rights in and to the above work to The Institute of Electrical and Electronics Engineers, Inc. (the "IEEE"). The undersigned hereby represents and warrants that the work is original and that he/she is the author of the work, except possibly for material such as text passages. figures, and data that clearly identify the original source. with permission notices from the copyright owners where required. The undersigned represents that he/she has the power and authority to make and execute this assignment.

In return for these rights, the IEEE recognizes the retained rights noted in Items I and 4 below, and grants to the above authors and employers for whom the work may have been performed a royalty-free license to use the material as noted in Items 2 and 3 . Item 5 stipulates that authors and employers must seek permission to republish in cases not covered by Items 2 3. and 4.

I. Employers (or authors) retain all proprietary rights in any process, procedure or artide of manufacture described in the work.

2. Authors/employers may reproduce or authorize others to reproduce the above work, material extracted verbatim from the above work, or derivative works for the author's personal use or for company use provided that the source and the IEEE copyright notice are indicated, that the copies are not used in any way that implies IEEE endorsement of a product or service of an employer, and that the copies themselves are not offered for sale. (See "Author/Employer Rights" overleaf.)

3. Authors/employers may make limited distribution of all or portions of the above work prior to publication if they inform the IEEE of the nature and extent of such limited distribution prior thereto.

4. In the case of work performed under a U.S. Government contract or grant IEEE recognizes that the U.S. Government has royalty-free permission to reproduce all or portions of the above work, and to authorize others to do so, for official U.S. Government purposes only, if the contract/grant so requires. (Appropriate documentation may be attached, but IEEE's Copyright Form MUST BE SIGNED. See "U.S. Government Employees/U.S. Government Contract Work" overleaf.)

5. For all circumstances not covered by Items 2. 3. and 4. authors/employers must request permission from the IEEE Copyrights Office to reproduce or authorize the reproduction of the work or material extracted verbatim from the work, including figures and tables.

Please see notes on "IEEE Obligations" as copyright holder.

In the event the above work is not accepted and published by the IEEE or is withdrawn by the author(s) before acceptance by the IEEE, this agreement becomes null and void.

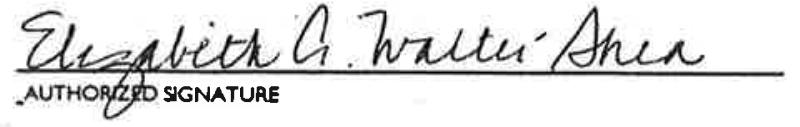

EMPLOYER FOR WHOM WORK WAS PERFORMED (if applicable)
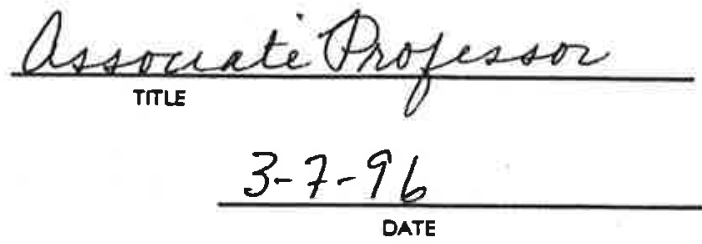

\section{JOINT AUTHORSHIP}

For jointly authored works, all the joint authors should sign. or one of the authors should sign as an authorized agent for the others. In the case of multiple authorship where one or more authors are Government employees but at least one author is not, that non-Government author should sign Part A of this form.

$149-00-0001$

Rev. $9 / 93$ 